\title{
The tin can method for determining moisture transport properties of concrete
}

\author{
Lars-Olof Nilsson ${ }^{1, *}$, and Kent Bergström ${ }^{2}$ \\ ${ }^{1}$ Moistenginst AB, 23196 Trelleborg, Sweden \\ ${ }^{2}$ Polygon-AK, 44240 Kungälv, Sweden
}

\begin{abstract}
Traditional methods for measuring moisture transport properties of concrete are timeconsuming, especially since thick specimens are required, and steady-state methods are preferred. Nonsteady state methods may be an alternative but the conditioning to uniform initial conditions is extremely difficult. The tin can method is, however, a good alternative under certain conditions and for certain concretes. Concrete is poured into a tin can and sealed cured in this way for at least a month. The can is opened, and the concrete is dried in a constant climate. Weight changes are recorded for several weeks. From these weight changes, the initial RH at start of drying, the drying climate and the desorption isotherm, the moisture transport coefficient or the moisture diffusion resistance factor are derived. The paper describes the theory behind the method and the unique conditions available for certain concretes that makes the method applicable. Examples of measurements are shown for a number of concretes and verification is done with the cup method on the very same concretes, with excellent results.
\end{abstract}

\section{Introduction}

Traditional methods for measuring moisture transport properties of concrete are time-consuming, especially since thick specimens are required, and steady-state methods are preferred. Most commonly used is the cupmethod where a disc of the concrete is placed as a lid on top of a glass or metal cup and the edges are sealed. The cup contains a saturated salt solution that gives a certain RH. The cup, with the lid, is placed in a controlled climate. The difference in RH over the concrete disc creates a moisture flow through the disc. Weight changes are determined until steady-state conditions are reached. From the flux of moisture and the moisture gradient over the disc the moisture transport coefficient can be evaluated.

An alternative steady-state method uses a much thicker specimen which means that a very long testing time is required, several years for a concrete with a low w/c (water-cement ratio) [1]. Once steady-state flow is reached the flux and the moisture profile is determined through the specimen. From the flux and the gradients at different depths, the moisture transport coefficients can be derived.

Non-steady state methods may be an alternative but the conditioning to uniform initial conditions is extremely difficult.

The tin can method may, however, be a good alternative under certain conditions and for certain concretes. Concrete is poured into a tin can and the can is sealed by a lid. The concrete is sealed cured in this way for at least a month to limit the changes of material properties during the test period. The can is opened, and the concrete is dried in a constant climate. Weight changes are recorded for several weeks. From these weight changes, the initial $\mathrm{RH}$ at start of drying, the drying climate and the desorption isotherm, the moisture transport coefficient or the moisture diffusion resistance factor are derived.

\section{Theory}

The evaluation of the weight changes of a specimen that dries is based on Equation (3.15) in Crank (1973) [2]. For a semi-infinite case, the amount of "diffusing substance" (i.e. moisture loss) M ( $t$ ) is given by

$$
M(t)=2 C_{0} \sqrt{\frac{D t}{\pi}}
$$

where $M(t)$ is the amount of moisture leaving the material, i.e. that is transported out from the surface $\left(\mathrm{kg} / \mathrm{m}^{2}\right)$,

$C_{0}$ is the constant initial concentration = moisture content) at all depths $\left(\mathrm{kg} / \mathrm{m}^{3}\right)$,

$D$ is the diffusivity $\left(\mathrm{m}^{2} / \mathrm{s}\right)$,

$t$ is the time (s).

The presumptions for equation (1) are that the surface concentration $C(\mathrm{x}=0)=0$. For a case with a surface concentration $>0$, e.g. $C(\mathrm{x}=0, \mathrm{t}=0)=C_{1}$ the equation will be

\footnotetext{
* Corresponding author: 1ars-olof.nilsson@moistenginst.se
} 


$$
\begin{gathered}
M(t)=2\left(C_{0}-C_{1}\right) \sqrt{\frac{D t}{\pi}}= \\
=2\left(C_{0}-C_{1}\right) \sqrt{\frac{D}{\pi}} \cdot \sqrt{t}=k \cdot \sqrt{t}
\end{gathered}
$$

By plotting the loss of weight, i.e. the loss of water, $M(\mathrm{t})$ versus the square-root of time, the data should follow a straight line as long as the presumptions above are valid. One presumption is that the case is "semi-infinite", i.e. the concentration $C$ (the moisture content) does not change at large depths. When such a change occurs, the data no longer follow a straight line.

From the slope of the straight line $k\left(\mathrm{~kg} /\left(\mathrm{m}^{2} \sqrt{\mathrm{s}}_{\mathrm{s}}\right)\right.$ the diffusivity $D$ of the material can be evaluated, if the two concentrations (moisture contents) $C_{0}$ and $C_{1}$ are known

$$
k=\frac{M(t)}{\sqrt{t}}=2\left(C_{0}-C_{1}\right) \sqrt{\frac{D}{\pi}}
$$

The diffusivity $D\left(\mathrm{~m}^{2} / \mathrm{s}\right)$ then follows from

$$
D=\frac{\pi k^{2}}{4\left(C_{0}-C_{1}\right)^{2}}
$$

The moisture transport property that usually is used in calculations, however, is not the diffusivity $D$ but the moisture transport coefficient $\delta_{\mathrm{v}}$ or the $\mu$-value.

The diffusivity $D$ for moisture, at a certain moisture level, is defined by

$$
D=\frac{\delta_{R H}}{\frac{d w}{d R H}}=\frac{\delta_{v}}{\frac{d w}{d R H}} \cdot v
$$

where $\mathrm{dw} / \mathrm{dRH}$ is the moisture capacity $\left(\mathrm{kg} / \mathrm{m}^{3}\right)$

$v_{\mathrm{s}}(\mathrm{T})$ is the vapour content at saturation at the temperature $\mathrm{T}$.

From the diffusivity $D$ the moisture transport coefficient can be determined if the (slope of the) sorption isotherm is known.

The difficulty with equation (4) is that the difference between the moisture contents $C_{0}$ and $C_{l}$ must be known. $C_{0}$ is the moisture content, at all depths, when drying starts and $C_{l}$ is the moisture content when drying has given the equilibrium moisture content at all depths, i.e. after a very long time.

For most materials it is very difficult to actually achieve a constant moisture content at all depths as initial conditions. One possibility is to saturate a specimen, with vacuum or with capillary suction, but for another level of initial moisture content the specimen has to be dried to equilibrium in a climate that gives the intended initial moisture content. This takes a very long time.

For low-w/c concrete, however, we have a unique opportunity that is not available for other materials; we can use the self-desiccation of the concrete. If a concrete is cured under sealed conditions, the chemical binding of water by the cement reactions will cause self-desiccation that will give the same, remaining evaporable moisture content at all depths, i.e. a constant moisture content as the theory requires.

One difficulty remains, however: to "avoid" having to determine the two moisture contents $C_{0}$ and $C_{l}$. The theory does not require that we know them both, "only" the difference between them, $C_{0}-C_{1}$ ! One way to quantify this difference is to instead determine the RH and utilize that we know the "moisture capacity", the slope of the sorption isotherm.

If we assume that the (de)sorption isotherm is a straight line between the moisture contents $C_{0}$ and $C_{1}$, that we prefer to call $w_{1}$ and $w_{2}$, the moisture capacity $\left(\mathrm{kg} / \mathrm{m}^{3}\right)$ can easily be expressed between $R H_{1}$ and $R H_{2}$

$$
\frac{d w}{d R H}=\frac{w_{1}-w_{2}}{R H_{1}-R H_{2}}
$$

This is a fair assumption for low w/c concrete.

The moisture content difference $C_{0}-C_{l}\left(\mathrm{~kg} / \mathrm{m}^{3}\right)$ in equations (2)-(4) can then be expressed as

$$
w_{1}-w_{2}=\frac{d w}{d R H}\left(R H_{1}-R H_{2}\right)
$$

Inserted into equation (4) gives

$$
D=\frac{\pi k^{2}}{\left(2 \frac{d w}{d R H}\left(R H_{1}-R H_{2}\right)\right)^{2}}
$$

The moisture transport coefficient $\delta_{\mathrm{v}}$ then follows from insertion into equation (5)

$$
\frac{\delta_{v}}{\frac{d w}{d R H}} \cdot v_{s}(T)=\frac{\pi k^{2}}{\left(2 \frac{d w}{d R H}\left(R H_{1}-R H_{2}\right)\right)^{2}}
$$

rearranged to

$$
\delta_{v}=\frac{\pi k^{2}}{4 \cdot v_{s}(T) \cdot \frac{d w}{d R H} \cdot\left(R H_{1}-R H_{2}\right)^{2}}
$$

This is the equation to be used.

\subsection{Evaluation}

The parameters in equation (10) can be determined in this way:

a. The parameter $\mathrm{k}$ is determined from the weight loss of a specimen drying one-way ; the weight loss is plotted against the square-root of time and the slope is expressed in $\mathrm{kg} /\left(\mathrm{m}^{2} \sqrt{\mathrm{s}}_{\mathrm{s}}\right.$,

b. $v_{\mathrm{s}}(\mathrm{T})$ is the vapour content at saturation at the temperature during the drying process,

c. $d w / d R H$ is the moisture capacity in the RH-interval $\left(\mathrm{RH}_{1}, \mathrm{RH}_{2}\right)$; if not known an estimate can be obtained from [2],

d. $\mathrm{RH}_{1}$ is the initial $\mathrm{RH}$, i.e. $\mathrm{RH}$ after self-desiccation, 
e. $\mathrm{RH}_{2}$ is $\mathrm{RH}$ in the surrounding climate during drying.

\subsection{The tin can method}

The tin can method can be described in the following, simple way.

- A tin can is filled with concrete and compacted.

- A lid is put on to seal the can.

- The can is stored at a controlled temperature for the intended curing time, at least one or two months.

- $\mathrm{RH}_{1}$ after self-desiccation is determined on a companion specimen, just before start of drying; for methods see [10].

- The lid is removed to start drying and the weight is determined once a week.

- The drying climate $\left(\mathrm{T}, \mathrm{RH}_{2}\right)$ is recorded during drying, for a month or two.

- Evaluation is done according to 2.1 and equation (10).

The tin can method is particularly well suited for (low-w/c) concrete as a prerequisite is a known, constant distribution of moisture when drying begins and the weight loss measurements begin. In concrete, cement reactions provide self-desiccation at all depths, which in normal cases (without extreme temperature conditions) gives rise to a decrease in moisture content and thus a decrease in RH. This RH should be measured as it is an important parameter in the evaluation.

The theory assumes that the material properties are constant in time. This means that the drying, and the weighing, must not start too early. Suitably, the concrete is allowed to cure for at least a month.

The theory also assumes that the material properties are constant with depth. Unfortunately, this is not the case when casting concrete and levelling the upper surface in some way. In concrete, the cement content is higher closer to the upper surface, as the largest aggregate grains will not fit at the top. This can play a certain role because it is the first part of the drying process that is part of the canning method and this part of the drying is largely done in the upper part of the concrete in the can.

\section{Experimental, tin can tests}

Four "Bascement" concretes were manufactured by Cementa $\mathrm{AB}$, cast into tin cans and compacted. The concrete compositions are shown in Table 1.
Table 1. The four (Bascement) concretes.

\begin{tabular}{|c|c|c|c|c|}
\hline Concrete & w/c & $\mathbf{C}(\mathrm{kg} / \mathrm{m} 3)$ & $\begin{array}{c}\text { RH1 at } \\
\text { 1 year }\end{array}$ & $\begin{array}{c}\text { dw/dRH } \\
(\mathrm{RH} 1, \mathrm{RH}) \\
(\mathrm{kg} / \mathrm{m} 3)[4]\end{array}$ \\
\hline 5 & 0.32 & 545 & 0.88 & 109 \\
\hline 2 & 0.40 & 470 & 0.92 & 122 \\
\hline 9.1A & 0.50 & 375 & 0.96 & 124 \\
\hline 10.1A & 0.36 & 510 & 0.91 & 112 \\
\hline
\end{tabular}

The "Bascement" is a CEM II/A-V 52,5 N with 10-15 \%fly ash

The sealed cans were stored at $+20^{\circ} \mathrm{C}$ for a year in the laboratory of Polygon AK. After determining the RH1 after self-desiccation, see Table 1, weights were determined by Kent Bergström during two months. The mass losses are plotted against the square root of time (in seconds) in Figure 1.

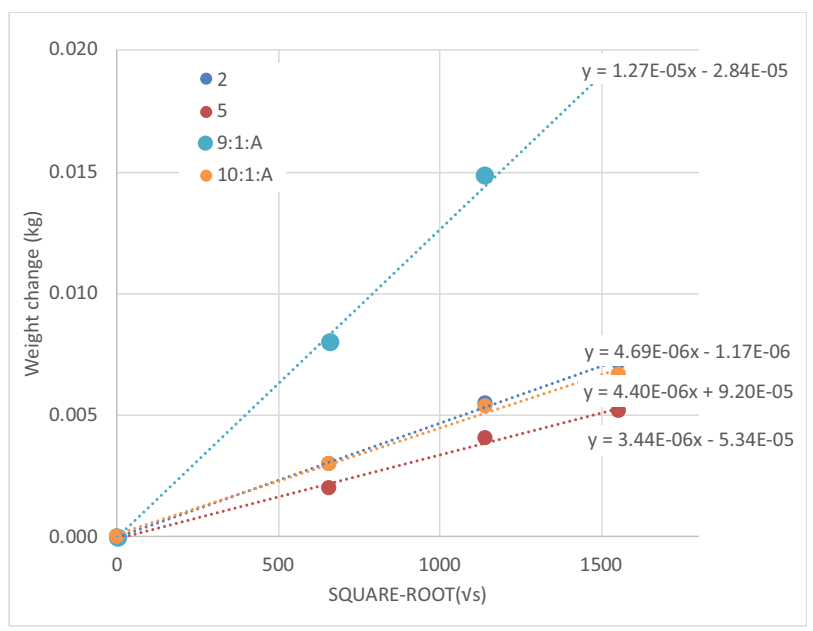

Fig. 1. Mass losses of the four concretes during two months.

All data points are on straight lines, as expected from theory as long as semi-infinite conditions apply, i.e. RH has not yet changed at the bottom of the can.

Evaluation according to 2.1 and equation (10) is shown in Table 2, using the data in Table 1.

Table 2. Evaluation of the mass loss measurements.

\begin{tabular}{|c|c|c|c|}
\hline Concrete & w/c & $\begin{array}{c}\text { Slope k } \\
(\mathbf{k g} / \mathbf{m} 2 \sqrt{\mathbf{s}})\end{array}$ & $\delta_{\mathbf{v}}(\mathbf{m} \mathbf{2} / \mathbf{s})$ \\
\hline 5 & 0.32 & 545 & $4.3 \mathrm{E}-8$ \\
\hline 2 & 0.40 & 470 & $5.8 \mathrm{E}-8$ \\
\hline $9.1 \mathrm{~A}$ & 0.50 & 375 & $3.5 \mathrm{E}-7$ \\
\hline $10.1 \mathrm{~A}$ & 0.36 & 510 & $5.8 \mathrm{E}-8$ \\
\hline
\end{tabular}




\subsection{Control calculations}

One way to verify the results of the method is to make calculations of the experimental conditions with given input data and evaluate the calculated drying results with the evaluation process described above. This was done with a soft-ware based on finite differences, KFX [4], and the results from the calculation coincided with the input data.

Calculations were also made to demonstrate the moisture profiles during the test to ensure that semiinfinite conditions prevailed. The results are shown in Figure 2 for one of the concretes, the one with the highest w/c.

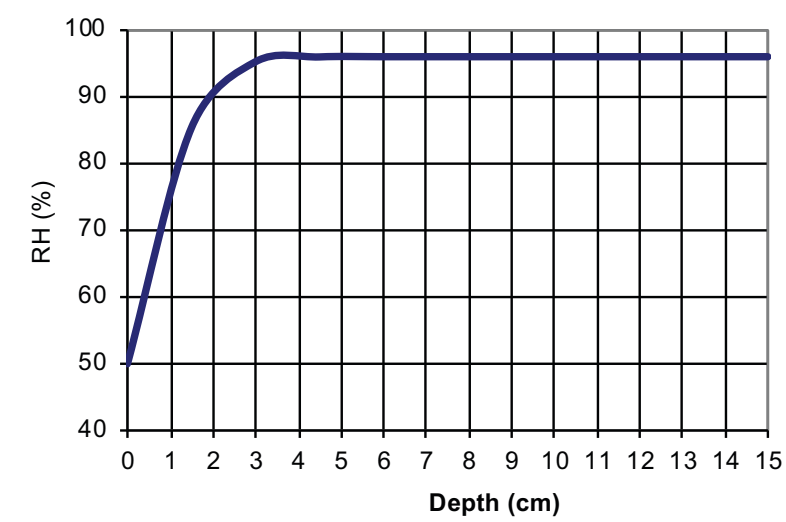

Fig. 2. Calculated RH-profile after two months of drying for concrete $9.1 \mathrm{~A}$ with $\mathrm{w} / \mathrm{c}=0.5$.

Figure 2 shows that semi-infinite conditions were present during the test; the drying affected the first 35 mm only.

\section{Experimental, cup tests}

The above theory is clear but should be verified by direct determination of the moisture transport coefficient by a traditional method: the cup method!

Such measurements have been performed, on slices cut from drilled cores from the relevant cans as above, i.e. exactly the same concretes.

\subsection{Specimens}

The four cans have been used to carry out measurements with the cup method on the same concrete as used in the can method. First, a $95 \mathrm{~mm}$ core was drilled out of the cans, with water cooling. Then about $30 \mathrm{~mm}$ thick slices were cut from this drilled core. Because the concrete can also contain horizontal pipes for RH measurements, not all slices could be used; 3-4 discs per concrete were useful.

The concrete discs were documented by the thickness being determined in a number of positions. The top discs in each core had an uneven upper surface after being in contact with the can's lid during curing.

The concrete discs were edge sealed with Platon Sealing Band and placed on a glass cup containing a saturated solution of potassium chloride, $\mathrm{KCl}$, which gives an RH of $85 \%$ inside the cup. The cups were placed in a climate room at Lund University with the climate $+20^{\circ} \mathrm{C}$ and $60 \% \mathrm{RH}$ and weighed once a week to begin with and then once every two weeks.

\subsection{Weight changes}

The concrete discs were slightly wetted in connection with drilling and sawing with water cooling and lost most weight during the first weights. The weight changes then became smaller and smaller as the moisture profile through the concrete slab gradually approached a stationary moisture profile. So far, weights have been determined for about eight months and the last three to four weights have been used for the evaluation. The cups will continue to be weighed to clarify how near stationary conditions have been reached at this time.

The weight changes are presented in diagram form in Figures 3 and 4.

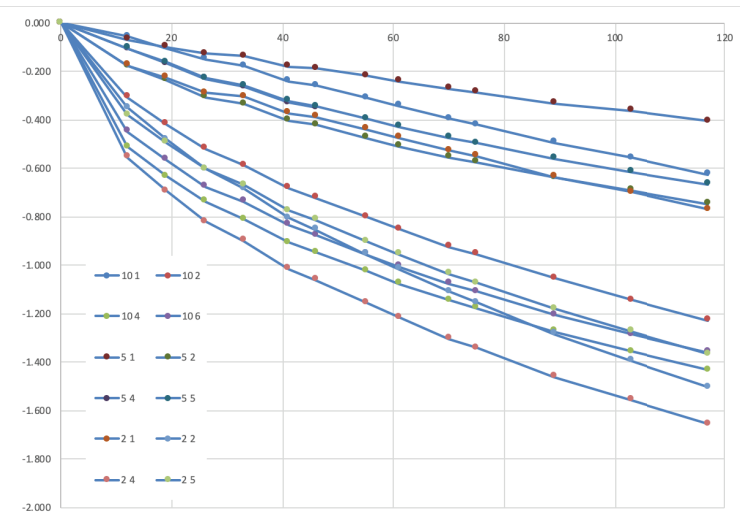

Fig. 3. Weight changes (grams) of cups with concretes 2, 5 and 10 (w/c 0.4, 0.32 and 0.36$)$ during the first four months.

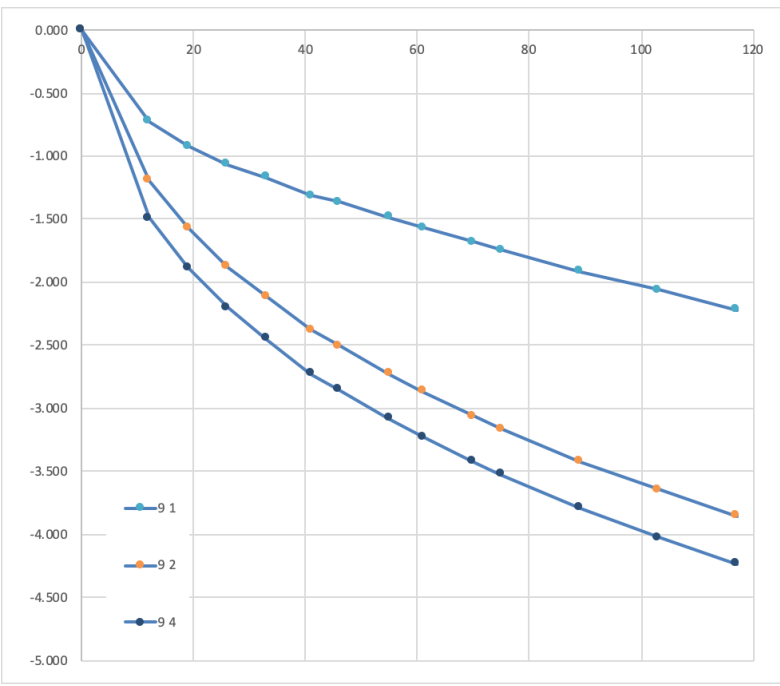

Fig. 4. Weight changes (grams) of cups with concrete 9 (w/c 0.5 ) during the first four months.

The top discs, closest to the originally drying surface, demonstrate a faster approach to a straight line, i.e to stationary conditions. The slopes of the mass loss curves of these discs are also smaller. 


\subsection{Evaluation}

From the three to four most recent weights, the slope has been evaluated, see Table 3 . After the weights in the above diagram, further weights have been made. These have confirmed that stationary flows have been obtained. The correlation coefficient is very close to 1.0.

The slope of the last part of the weight change curves has been converted to moisture flows in grams per $\mathrm{m} 2$ and second; the diameter is $95 \mathrm{~mm}$. With the respective thicknesses and the climate on either side of the concrete slab, the moisture transport coefficient $\delta \mathrm{v}$ can then be evaluated. The results are reported in Table 3 .

Table 3. The cup's weight change per unit of time in the last month and evaluated moisture transport coefficients.

\begin{tabular}{|c|c|c|c|c|c|}
\hline \multirow{2}{*}{ Disc } & Slope & \multirow{2}{*}{ R2 } & $\begin{array}{c}\text { Moisture } \\
\text { flow }\end{array}$ & $\begin{array}{c}\text { Thick- } \\
\text { ness }\end{array}$ & \\
\cline { 4 - 6 } & g/day & & g/(m2s) & $\mathrm{mm}$ & $(\mathrm{m} 2 / \mathrm{s})$ \\
\hline 10.1 & 0.0053 & 0.9994 & $8.65 \mathrm{E}-06$ & 29.6 & $5.9 \mathrm{E}-08$ \\
\hline 10.2 & 0.0060 & 0.9985 & $9.80 \mathrm{E}-06$ & 28 & $6.3 \mathrm{E}-08$ \\
\hline 10.4 & 0.0052 & 0.9971 & $8.49 \mathrm{E}-06$ & 30.2 & $5.9 \mathrm{E}-08$ \\
\hline 10.6 & 0.0049 & 0.9995 & $8.00 \mathrm{E}-06$ & 30 & $5.5 \mathrm{E}-08$ \\
\hline 9.1 & 0.0119 & 0.9985 & $1.94 \mathrm{E}-05$ & 27.5 & $1.2 \mathrm{E}-07$ \\
\hline 9.2 & 0.0128 & 0.9996 & $2.09 \mathrm{E}-05$ & 30.5 & $1.5 \mathrm{E}-07$ \\
\hline 9.4 & 0.0129 & 0.9995 & $2.10 \mathrm{E}-05$ & 30.5 & $1.5 \mathrm{E}-07$ \\
\hline 5.1 & 0.0033 & 0.9895 & $5.39 \mathrm{E}-06$ & 30 & $3.7 \mathrm{E}-08$ \\
\hline 5.2 & 0.0041 & 0.9988 & $6.70 \mathrm{E}-06$ & 30.4 & $4.7 \mathrm{E}-08$ \\
\hline 5.4 & 0.0042 & 1.0000 & $6.85 \mathrm{E}-06$ & 31 & $4.9 \mathrm{E}-08$ \\
\hline 5.5 & 0.0043 & 0.9977 & $7.02 \mathrm{E}-06$ & 31 & $5.0 \mathrm{E}-08$ \\
\hline 2.1 & 0.0054 & 0.9964 & $8.82 \mathrm{E}-06$ & 30.1 & $6.1 \mathrm{E}-08$ \\
\hline 2.2 & 0.0058 & 0.9987 & $9.47 \mathrm{E}-06$ & 29.5 & $6.5 \mathrm{E}-08$ \\
\hline 2.4 & 0.0069 & 1.0000 & $1.13 \mathrm{E}-05$ & 30.3 & $7.9 \mathrm{E}-08$ \\
\hline 2.5 & 0.0069 & 0.9988 & $1.13 \mathrm{E}-05$ & 31 & $8.1 \mathrm{E}-08$ \\
\hline
\end{tabular}

The air layer between the saturated saline solution and the bottom of the concrete disc has a certain moisture transport resistance which means that the $\mathrm{RH}$ at the bottom surface of the concrete disc is slightly lower than above the saline solution. However, with the small moisture flows that are present here, this effect is completely negligible; $\mathrm{RH}$ can be at most $0.2 \% \mathrm{RH}$ lower than $85 \% \mathrm{RH}$.

\section{Results and discussion}

The moisture transport coefficients for each concrete disc are shown in the diagram below. In this the moisture transport coefficients from the measurements with the can method for the four concrete have also been included. Note that the can method for concrete 9 , w/c 0.5 , has a completely different RH interval than the other concretes.

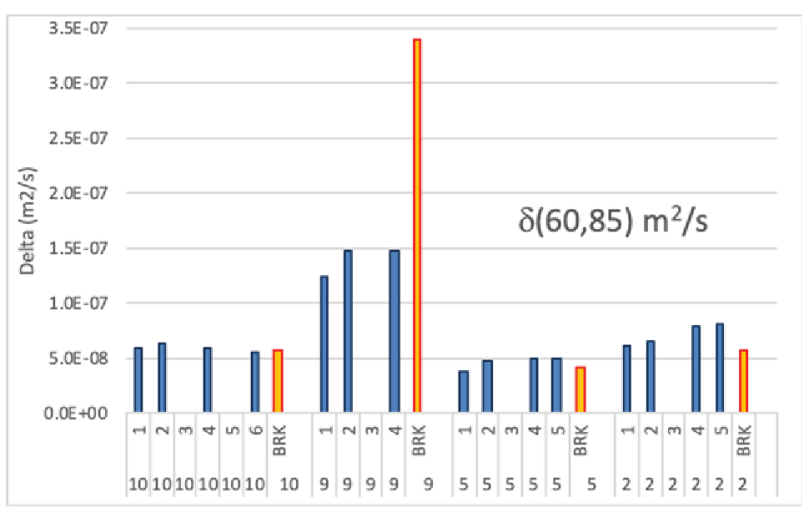

Fig. 5. The moisture transport coefficient $\delta(\mathrm{m} 2 / \mathrm{s})$ for the different concrete discs $1-6$, in the RH interval (60.85) and for the concrete with the can (BRK) method, in different $\mathrm{RH}$ intervals, see the text.

The determined moisture transport coefficients appear to be of a reasonable order of magnitude. The results from the cup measurements surprisingly well match the results from the can method; for the concrete with the lower vct, this is very good, even though the RH intervals are not the same. Olsson et al (2018) [7] and Hedenblad (1993) [2] showed that the moisture dependency is very small when the w/c is about 0.4 or less. This indicates that the can method can be a method to quickly get an idea of a new concrete's moisture transport properties.

For w/c 0.5 (concrete 9), $3.4 \cdot 10^{-7} \mathrm{~m}^{2} / \mathrm{s}$ was obtained with the can method and $1.2-1.8 \cdot 10^{-7} \mathrm{~m}^{2} / \mathrm{s}$ with the cup method. However, with the can method, the RH interval was different, 50-96\% RH, which of course should give a higher value of the moisture transport coefficient. Hedenblad (1993) [2] received about $3 \cdot 10^{-7} \mathrm{~m}^{2} / \mathrm{s}$ in the range $60-85 \%$ RH. For concrete with w/c lower than 0.4 we have no reliable data to compare with.

The early results of the cup measurements indicated that the concrete surface layer, about $30 \mathrm{~mm}$, seemed to be more impermeable than at greater depths [9]. This was observed for all four concretes. It is moisture transport in this surface layer that most affects the result of a short-term measurement with the can method. The comparison in Figure 5 shows that the data for the top disc No. 1 coincide especially well with the data from the can method.

Later weigh measurements have shown that discs 2-6 still had not reached stationary conditions after four months. This is not strange since these discs had an even, constant moisture profile after being cut out from the core and had to change the moisture profiles to something close to a straight line from $60 \% \mathrm{RH}$ at the top surface to $85 \% \mathrm{RH}$ at the bottom surface. The top discs No. 1 had already such a moisture profile initially, cf. Figure 2.

The results of the cup measurements are also shown in the diagram below, as a function of $w / c$ for the four concretes. 


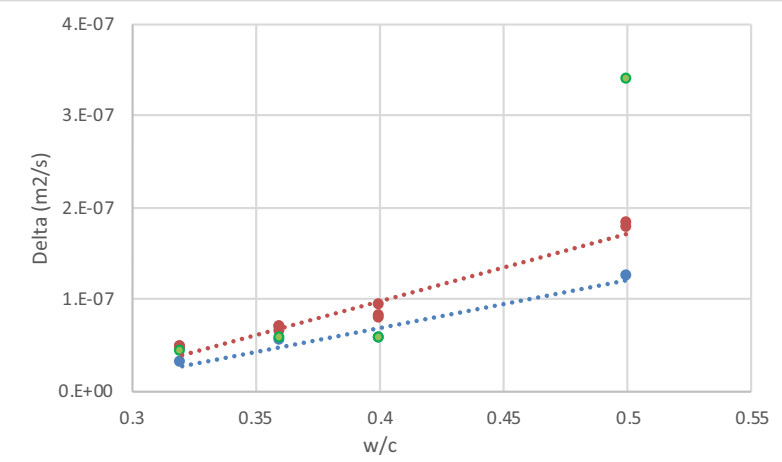

Fig. 6. The moisture transport coefficients $\delta(\mathrm{m} 2 / \mathrm{s})$ for the four concretes

- for the $30 \mathrm{~mm}$ thick surface layer (blue, lower), in the $\mathrm{RH}$ range $(60,85)$

- for the $30 \mathrm{~mm}$ thick layers of 30-150 mm deep (red, top), in the RH range $(60,85)$

- from the can measurements, i.e. for the surface layers (green), in different $\mathrm{RH}$ ranges from $50 \% \mathrm{RH}$ to that given by self-drying, i.e. about $95 \% \mathrm{RH}$ for w/c 0.5 and $<90 \% \mathrm{RH}$ for $\mathrm{w} / \mathrm{c}<0.4$.

\subsection{Carbonation}

If the can was completely sealed with the lid, the concrete surface has not been carbonated at start of drying. When drying then starts, and the can lose weight due to drying, it also begins to absorb carbon dioxide which increases weight, i.e. decreases the weight change. Carbonation also has the effect of releasing water, one water molecule per carbon dioxide molecule, which corresponds to $18 / 44$ of the weight gain due to carbon dioxide uptake. This water slightly increases the moisture content of the carbonated layer. At the same time, the carbonated layer has slightly altered moisture fixation and moisture transport properties [3]. All in all, carbonation at the same time as drying means that the measured weight change underestimates the moisture output somewhat. The can method would therefore yield a moisture transport coefficient that is slightly smaller than the actual one.

An estimate of the effect of carbonation has been made using a model for carbon dioxide absorption due to carbonation [6]. In this model, data for the concrete above with w/c 0.5 have been entered (w/c 0.5 , cement content $375 \mathrm{~kg} / \mathrm{m}^{3}$ ), proportion of Portland cement clinker in the cement $80 \%, \mathrm{RH}=50 \%$ ). The absorption of carbon dioxide during the first year is shown in the diagram below.

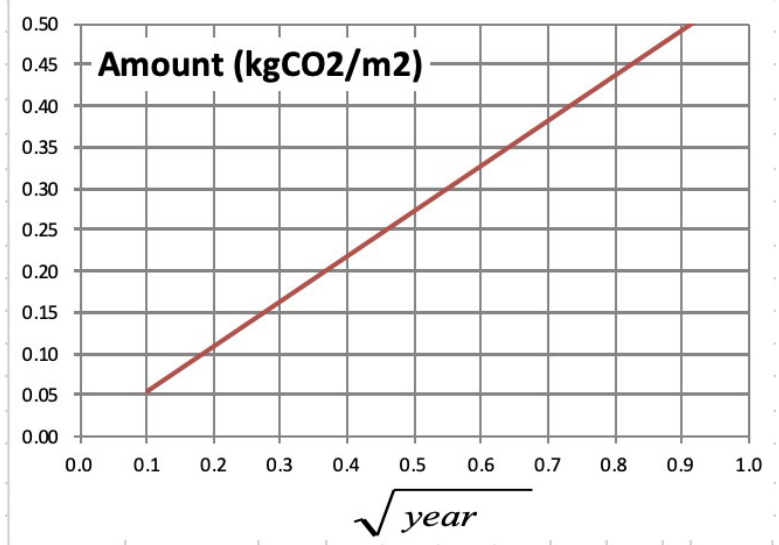

Fig. 7. Calculated carbon dioxide absorption due to carbonation of Bascement concrete with w/c 0.5 during the first year, according to a model according to Nilsson (2011) [6].

In the evaluation example above, weight changes over 28 days were determined, corresponding to $28 / 365$ $=0.077$ years or 0.28 years. In the diagram above, it gives a weight gain due to carbon dioxide absorption of about $0.15 \mathrm{~kg} / \mathrm{m}^{2}$. The measured weight loss was 0.019 / $0.028=0.68 \mathrm{~kg} / \mathrm{m}^{2}$. Carbon dioxide absorption has thus reduced the weight change by about $20 \%$, i.e. the moisture transport coefficient should be about $20 \%$ larger than in the example above.

\section{Conclusions}

1. The can method seems to be a quick and easy way to determine the moisture transport properties of concrete.

2. The method has been verified against cup measurements and given good agreement.

3. The method is best suited for concrete with low w/c because it only gives an average value in a certain $\mathrm{RH}$ interval. It cannot give an $\mathrm{RH}$ dependency without performing a series of measurements.

4. The method measures the properties of the concrete surface layer. The thickness of the surface layer depends on the maximum stone size.

5. The method is not suitable for young concrete. The method requires a number of weeks of measurement time and gives an average value during the measurement time. The concrete should therefore have been cured at least one month before measurement starts.

6. The evaluation requires that the RH after self-drying be determined just before the measurement starts. It should be done on a separate test body and not in tubes in the can measurement.

7. Concrete in the can should be levelled and not come in direct contact with the lid, in order for the concrete surface to be well defined. The "thickness" of the concrete layer is determined. Possibly the concrete is compacted with the can turned with the lid down.

8. The can concrete must be cured at constant temperature and drying should be done in a constant climate with known T \& RH. 
9. The first weighing takes place immediately after removing the lid. Weighing is then done once or twice a week; date and time are noted.

10. The method gives the moisture transport properties in the RH interval between self-desiccation and the drying climate used. For low-w/c concrete, extrapolation can take place outside this $\mathrm{RH}$ range.

11. The method gives the moisture transport properties of the concrete surface layer, $<30 \mathrm{~mm}$.

12. Carbonation reduces weight change due to moisture loss, which causes the moisture transport coefficient to be somewhat underestimated, a systematic error; it can be about $20 \%$ larger than the method gives. Careful determination requires that carbonation be taken into account, for example according to Nilsson (2011) [6].

13. The method contains a number of sources of error that contribute to the measurement uncertainty. The biggest sources of error are judged to be the RH measurement and the estimation of the moisture capacity. That the concrete shrinks slightly and a thin crack is formed between the can and the concrete has negligible effect on the drying [8].

Polygon Sverige AB is acknowledged for funding the project.

\section{References}

1. Crank, J. (1973). Second edition, Oxford University Press

2. Hedenblad, G. (1993). Report TVBM-1014, Div. Building Materials, Lund university 1993

3. Kropp, J. (1983) Karbonatisierung und Transportvorgänge in Zementstein. Dissertation Universität Karlsruhe.

4. Nilsson, L-O (1980). Report TVBM-1003, Div. Building Materials, Lund university 1980

5. KFX, - Software for predicting heat and moisture variations, M. Rodhe, Dept- of Building Materials, Chalmers university of technology, Göteborg 2002.

6. Nilsson, L.-O. Report TVBM-3158, Div. Building Materials, Lund university (2011)

7. Olsson, N., Nilsson, L.-O., Åhs, M., BaroghelBouny, V. Cement and Concrete Research, 106 (2018) pp. 23-32.

8. Åhs, M. Presentation at Moisture Center Information Day, Göteborg March 27, 2019.

9. Nilsson, L.-O. Report 1922, Moisture Engineering Institute Moistenginst AB, Trelleborg 2019-10-01, www.moistenginst.com

10. Nilsson, L.-O. (ed.). State-of-the-Art Report, RILEM TC-248 MMB. Report Volume 26 published by Springer http://www.springer.com/9783319742304 